\title{
Armazenamento refrigerado de atemoia 'Gefner' em atmosfera modificada
}

\author{
Refrigerated storage of 'Gefiner' atemoy under modified atmosphere
}

Almacenamiento refrigerado de atemoy 'Gefner' en atmósfera modificada

\section{Resumo}

Atemoia é um fruto muito perecível que necessita de cuidados durante o armazenamento. Assim, esta pesquisa teve como objetivo avaliar a qualidade pós-colheita de atemoias 'Gefner' armazenadas sob atmosfera modificada. Os frutos foram colhidos em maturidade fisiológica na empresa Kabocla na Chapada do Apodi e transportados para o IFCE Campus Limoeiro do Norte (CE), onde foram selecionados e sanitizados. Posteriormente, foram aplicados os tratamentos: (T1) Controle; (T2) Policloreto de vinila- PVC em tempo parcial; (T3) PVC em tempo total e (T4) fécula de mandioca a $3 \%$. Os frutos foram armazenados em câmara fria a $15 \pm 4{ }^{\circ} \mathrm{C}$ e umidade relativa $85 \pm 4 \%$. Utilizou-se delineamento inteiramente casualizado em esquema fatorial $4 \times 6$, em que o primeiro fator constou dos tipos de recobrimentos e o segundo dos tempos de armazenamento $(0,3,6,9,12$ e 15). A cada três dias foram analisadas: perda de massa fresca, firmeza da polpa, aparência externa, cor da casca, índice de rachadura, acidez titulável, $\mathrm{pH}$, sólidos solúveis, amido, açúcares totais, ratio e vitamina $\mathrm{C}$. Resultados expressivos foram observados para perda de massa dos frutos recobertos com fécula de mandioca a $3 \%$ e controle com 5,93 e $7,12 \%$, respectivamente. Ao longo do armazenamento todos os frutos apresentaram perda de firmeza e aumento do índice de rachaduras. A fécula de mandioca a 3\% ocasionou perda de qualidade externa e atrasou mudanças de coloração da casca juntamente com os outros recobrimentos, atrasando o início das rachaduras. Os recobrimentos proporcionaram vida útil de 9 dias.

Palavras-chave: Anonáceas; Pós-colheita; Recobrimentos.

\section{Summary}

Atemoya is a very perishable fruit that needs care during storage. Thus, this research aimed to evaluate the postharvest quality of 'Gefner' atemoyas stored in modified atmosphere. The fruits were harvested at physiological maturity at the company Kabocla in Chapada do Apodi and transported to the IFCE Campus Limoeiro do Norte (CE), where they were 
selected and sanitized. Subsequently, the following treatments were applied: (T1) Control; (T2) part-time PVC; (T3) full-time PVC and (T4) $3 \%$ cassava starch. The fruits were stored in a cold chamber at $15 \pm 4^{\circ} \mathrm{C}$ and relative humidity $85 \pm 4 \%$. A completely randomized design in a $4 \times 6$ factorial scheme was used, in which the first factor consisted of the types of coatings and the second of the storage times $(0,3,6,9,12$ and 15). Every three days, the following were analyzed: fresh mass loss, flesh firmness, external appearance, skin color, crack index, titratable acidity, pH, soluble solids, starch, total sugars, ratio and vitamin C. Expressive results were observed for weight loss of fruits coated with $3 \%$ cassava starch and control with 5.93 and 7.12\%, respectively. During storage, all fruits showed loss of firmness and increased cracking index. The $3 \%$ cassava starch caused a loss of external quality and delayed changes in the color of the skin along with the other coatings, delaying the onset of cracks. The coatings provided a shelf life of 9 days.

Keywords: Anonaceous; Coverings; Post-harvest.

\section{Resumen}

La atemoia es una fruta muy perecedera que necesita cuidados durante el almacenamiento. El objetivo de este trabajo fue validar la calidad poscosecha de atemoyas almacenados 'Gefner' con refrigeración y atmósfera modificada. Los frutos se cosechan en madurez fisiológica en la empresa Kabocla en Chapada do Apodi y se transportan a la planta piloto de Frutas y Hortalizas en el IFCE Campus Limoeiro do Norte (CE). Fueron seleccionados y desinfectados con una solución clorada a 50 ppm / 15 minutos. Después, se aplicaron los siguientes tratamientos: (T1) Chequeo; (T2) PVC a tiempo parcial; (T3) PVC de tiempo completo y (T4) amidón de mandioca al 3\%. Los frutos se enmarcan en cámara fría a $15 \pm 4{ }^{\circ} \mathrm{C}$ y humedad relativa de $85 \pm 4 \%$. El diseño experimental utilizado fue aleatorizado internamente en un esquema factorial $4 \times 6$, con tres repeticiones de tres frutos por parcela, por un total de 116 frutos. La primera parte está compuesta por los tipos de revestimiento y la segunda parte de los tempos de alcenamiento $(0,3,6,9,12$ y 15). Cada tres días se analizó lo siguiente: pérdida de masa fresca, firmeza de la pulpa, aspecto externo, color de la cáscara, índice de grietas, titulación de acidez, $\mathrm{pH}$, sólidos solubles, almidón, azúcares totales, proporción y vitamina C. Se observaron resultados expresivos para la pérdida de peso de frutos recubiertos con 3\% de almídon de mandioca y control con 5.93 y $7,12 \%$, respectivamente. Durante el almacenamiento todos los frutos, mostraron perdida de firmeza y aumiento del índice de grietas. El almíndon de mandioca al 3\% provocón uma perdida de la calidad externa y retrasó los cambios em el color de la cáscara junto con los demás recubrimientos, retrasando la aparición de grietas. Los recubrimientos proporcionaron una vida útil de 9 días.

Palabras clave: Anonáceo; Postcosecha; Revestimientos.

\section{Introdução}

A atemoia (Annona squamosa x Annona cherimola Mill.) é um fruto climatérico que apresenta curta vida pós-colheita quando armazenada sob temperatura ambiente e susceptível a uma série de desordens fisiológicas quando exposta a temperatura de refrigeração. É um fruto muito perecível que depende de cuidados como época e manuseio na colheita, embalagem e transporte do produto (Torres, 2008; Santos, 2009). Ainda são poucos os estudos realizados com a conservação pós-colheita de atemoia, o que justifica a necessidade de maiores pesquisas, pois essa cultura vem demonstrando crescimento elevado e interesse de exploração em razão do lucrativo retorno comercial (Silva et al., 2009).

Técnicas que visam à redução de perdas pós-colheita de atemoia relacionam-se à temperatura de refrigeração além de aplicação de embalagem plástica e película de fécula de mandioca (Silva et al., 2009; Santos, 2009). O armazenamento em atmosfera modificada utilizando filmes plásticos promovem um aumento da concentração de gás carbônico e a diminuição de oxigênio na atmosfera ambiental e consequentemente a menor velocidade de respiração dos frutos, o que acarreta uma maior vida útil (Lima, 2016). A atmosfera modificada pode ser resumida como presença de barreira artificial à difusão de gases em torno do produto, aumentando níveis de dióxido de carbono $\left(\mathrm{CO}_{2}\right)$ e diminuindo os níveis de oxigênio $\left(\mathrm{O}_{2}\right)$, resultando na alteração na concentração de etileno e vapor d'água e em alterações em outros compostos voláteis (Silva et al., 2009).

Os filmes plásticos à base de polietileno ou cloreto de polivinila (PVC), devido a sua praticidade, ao custo relativamente baixo e à alta eficiência tem sido bastante utilizados, principalmente quando associados ao armazenamento refrigerado para evitar perdas de frutos (Silva et al., 2009).

A fécula de mandioca é uma matéria-prima empregada em estudos para a elaboração de filmes biodegradáveis, pois formam películas transparentes, resistentes, sem pegajosidade e melhoram a aparência dos frutos, tornando-os mais brilhantes, de bom aspecto e atrativos (Mohr et al., 2014). 
Conforme Prill et al. (2012) o armazenamento refrigerado é essencial para tornar lenta a degradação química, física, fisiológica dos produtos frescos. O armazenamento refrigerado associado à utilização da atmosfera modificada destaca-se como uma possibilidade no prolongamento da vida útil dos frutos, refletindo na dilatação do período de comercialização (Santos, 2009).

Tendo em vista esse aspecto e no sentido de contribuir para o melhor entendimento dos processos fisiológicos envolvidos na conservação pós-colheita de anonáceas, esta pesquisa teve como objetivo avaliar o efeito do armazenamento refrigerado de atemoia 'Gefner' sob atmosfera modificada.

\section{Metodologia}

\subsection{Colheita e preparo dos frutos}

Os frutos de atemoias 'Gefner' utilizados na presente pesquisa foram colhidos em maturidade fisiológica na empresa Kabocla, localizada no município de Limoeiro do Norte - CE. Em seguida foram embalados em redes de poliestireno expandido, acondicionados em caixas plásticas e transportados para a Planta Piloto de Processamento de Frutos e Hortaliças do Instituto Federal de Educação, Ciência e Tecnologia do Ceará Campus Limoeiro do Norte para preparo dos frutos e condução do experimento.

Inicialmente, os frutos foram selecionados em função de algumas características principais, tais como: tamanho, cor e ausência de danos. Posteriormente foram lavados e sanitizados em solução clorada na concentração de 50 ppm por 15 minutos.

\subsection{Tratamentos realizados}

Os frutos de atemoias 'Gefner' foram divididos em grupos principais, considerando-se parte dos frutos que foi submetida a aplicação de atmosfera modificada através de cobertura com fécula de mandioca na concentração de 3\%; enquanto outra parte foi recoberta com filme de PVC comercial Alp Film ${ }^{\circledR}$, esticável e autoaderente, com $15 \mu \mathrm{m}$ de espessura; e os demais frutos foram mantidos sem atmosfera modificada representando assim, os frutos do controle.

Para o preparo do biofilme foram diluídos $30 \mathrm{~g}$ de fécula de mandioca em $1000 \mathrm{~mL}$ de água destilada e posteriormente a solução foi aquecida a $70^{\circ} \mathrm{C}$ até geleificação. Em seguida, a solução foi deixada a temperatura ambiente até resfriamento para posterior imersão dos frutos.

Para aplicação do biofilme nos frutos de atemoias 'Gefner', esses foram imersos por 1 minuto na solução e após secagem e fixação da solução na superfície dos frutos, os mesmos foram acomodados em bandejas de isopor com 3 frutos em cada bandeja. O outro grupo de frutos foi recoberto com filme PVC Alp Film ${ }^{\circledR}$ e acondicionados em bandejas de isopor.

Os frutos de atemoia 'Gefner' foram armazenados por 15 dias a temperatura de $15^{\circ} \mathrm{C}\left( \pm 4{ }^{\circ} \mathrm{C}\right)$ e umidade relativa de $85 \%( \pm 4 \%)$ com a realização das análises a cada 3 dias de armazenamento.

O delineamento experimental utilizado foi o inteiramente casualizado, em esquema fatorial $4 \times 6$, com três repetições de três frutos por parcela, totalizando 116 frutos. Os fatores avaliados consistiram nos tratamentos aplicados aos frutos (frutos embalados em PVC em tempo parcial, frutos embalados em PVC em tempo total, frutos embalados em fécula de mandioca a 3\% e frutos do controle) e nos tempos de armazenamento $(0,3,6,9,12,15$ dias). Os resultados foram avaliados por análise de variância para verificar a significância dos efeitos nas respostas obtidas.

No presente experimento foram utilizados quatro tratamentos aplicados aos frutos, conforme demostrado na Figura 1 abaixo: 
Figura 1. Tratamentos (T1 - Frutos sem recobrimento (controle); $\mathrm{T} 2$ - Frutos revestidos individualmente com PVC em tempo parcial; T3 - Frutos revestidos individualmente com PVC em tempo total; T4 - Frutos revestidos individualmente com biofilme de fécula de mandioca a 3\%) empregados nos frutos de atemoia 'Gefner'. IFCE, Limoeiro do Norte-CE, 2013.
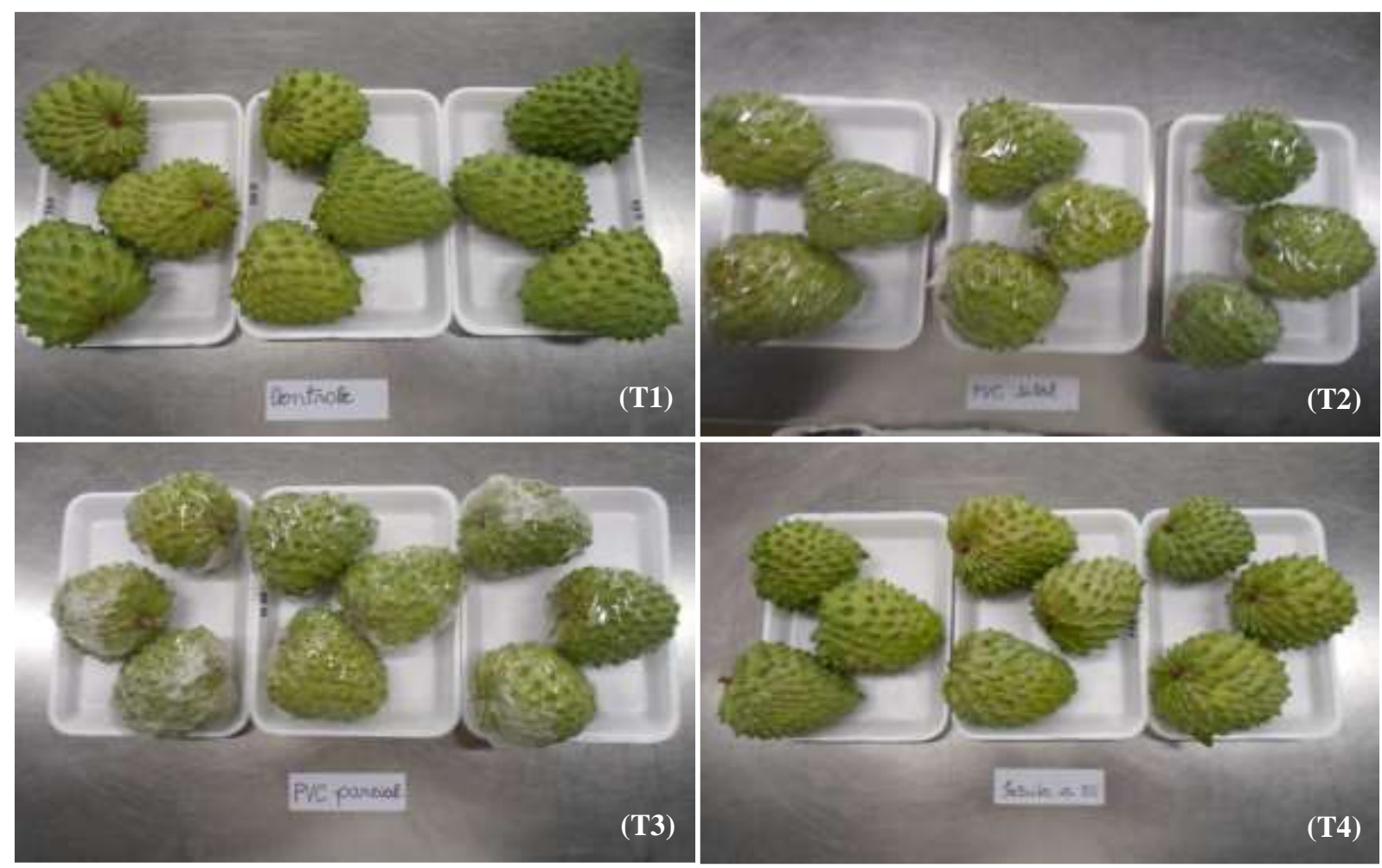

\subsection{Características avaliadas}

Fonte: Autores.

Os frutos de atemoia 'Gefner' foram avaliados no dia da colheita e a cada três dias de armazenamento quanto as características físicas e físico-químicas, com análises realizadas no Laboratório de Química de Alimentos do Instituto Federal de Educação, Ciência e Tecnologia - IFCE, Campus Limoeiro do Norte (CE), conforme descritas a seguir:

\subsubsection{Características físicas}

- Perda de massa: os frutos de cada tratamento e em cada época de avaliação foram pesados individualmente, utilizandose balança eletrônica com precisão de $0,1 \mathrm{~g}$. A diferença de massa entre as avaliações foi acumulada durante a evolução do experimento, considerando-se a diferença entre a massa inicial do fruto e aquela obtida em cada período de amostragem;

- Firmeza da polpa: a firmeza da polpa foi medida por meio de penetrômetro manual marca Soloeste ${ }^{\circledR}$, com ponteira de $8 \mathrm{~mm}$ de diâmetro realizada em três regiões equatoriais e equidistantes do fruto após remoção de pequena porção da casca. A leitura foi obtida em libras e convertida em Newton (N) multiplicando-se pelo fator 4,448;

- Aparência externa: a aparência externa dos frutos foi avaliada utilizando escala subjetiva de 5 a 1 , de acordo com a intensidade de depressões, murcha, ataque fúngico e manchas escuras na superfície do fruto, de acordo com a seguinte escala subjetiva: nota 5 (ausência de depressões, murcha ou ataque de micro-organismos); nota 4 (traços de depressões e/ou murcha); nota 3 (leve depressões e/ou murcha); nota 2 (depressões e/ou murcha com média intensidade e leve ataque de micro-organismos) e nota 1 (depressões e murcha com intensidade severa e ataque de micro-organismos), sendo considerado impróprio para a comercialização os frutos que obtiveram nota igual ou menor que 3 (Lima et al., 2003); 
- Cor da casca: A coloração da casca e da polpa dos frutos inteiros foi determinada por leituras obtidas a partir da emissão de um feixe de luz da lente do colorímetro (Konica Minolta spectrophotometer CM - 3500d), medidos por reflectância. Os resultados foram expressos de acordo com as coordenadas CIE (Commission Internacionale de LEclaraige) lab (color space) que incluem as variáveis $\mathrm{L}^{*}, \mathrm{a}^{*} \mathrm{e} \mathrm{b}^{*}$, onde $\mathrm{L}^{*}$ é uma medida da luminosidade de um objeto e varia do 0 (para o preto) até ao 100 (para o branco), a* é uma medida do vermelho ( $\mathrm{a}^{*}$ positivo) ou do verde (a* negativo) e b* é uma medida do amarelo (b* positivo) ou do azul (b* negativo). Para a cor da casca, foram realizadas duas leituras por fruto, em lados opostos da região equatorial e na base das terminações estilares (Lima et al., 2003). A partir dos valores L*, a* e b* foram calculados o ângulo hue $\left({ }^{\circ} \mathrm{H}\right)$ e índice de saturação croma $(\mathrm{C})$. Para cada repetição foi utilizada a média de duas leituras por fruto;

- Índice de rachadura: foi observado na superfície da casca dos frutos o surgimento de rachaduras e realizada contagem a cada tempo de armazenamento (Barbosa et al., 2011);

\subsubsection{Características físico-químicas}

- Acidez Total Titulável: foi determinada por método titulométrico com solução de NaOH 0,1 M e fenoftaléina como indicador (IAL, 2008);

- $p H$ : a determinação do potencial hidrogeniônico $(\mathrm{pH})$, foi realizada através de leitura em potenciômetro eletrônico sob agitação calibrado com soluções tampão de pH 4,0 e 7,0, conforme metodologia recomendada pelo Instituto Adolf Lutz (2008);

- Sólidos Solúveis: a polpa foi triturada em homogeneizador doméstico e em seguida diluída na concentração de $1 \mathrm{~g}$ de polpa para $1 \mathrm{~mL}$ de água destilada (1:1) e homogeneizada com bastão de vidro e, posteriormente, filtrada em papel de filtro. Tomando-se duas gotas do filtrado, mediu-se o teor de sólidos solúveis através de refratômetro digital portátil Modelo Atago, de acordo com a metodologia recomendada pelo Instituto Adolf Lutz (2008). Os resultados foram multiplicados por 2 para compensar a diluição, sendo estes expressos em ${ }^{\circ}$ Brix;

- Amido: determinado pelo método DNS (3,5 - Dinitro - Salicílico, Sigma), conforme metodologia descrita por Miller (1959);

- Açúcares totais: determinados pelo método DNS (3,5 - Dinitro - Salicílico, Sigma), conforme metodologia descrita por Miller (1959);

- Ratio: obtido pela relação entre os sólidos solúveis e a acidez titulável;

- Vitamina C: determinado pelo método colorimétrico com solução DFI (2,6 diclorofenolindofenol (0,02\%) até coloração rósea claro permanente descrito por Stroehcker e Henning (1967). Os resultados foram expressos em miligramas de ácido ascórbico em $100 \mathrm{~g}$ de polpa.

\section{Resultados e discussões}

\section{1. Características físicas}

- Perda de massa

Observou-se aumento da perda de massa durante o período de armazenamento para todos os tratamentos (Figura 1). As maiores porcentagens de perda de massa foram verificadas principalmente nos frutos recobertos com biofilme a base de fécula 
de mandioca a 3\% (T4) e nos frutos controle (T1) com valores máximos ao final do armazenamento de 5,93 e 7,12\%, respectivamente.

Figura 1. Perda de massa (\%) de frutos de atemoia 'Gefner' submetidos a diferentes tipos de recobrimento armazenados a $15 \pm$ $4^{\circ} \mathrm{C}$ e $85 \pm 4 \%$ de Umidade Relativa durante 15 dias. IFCE, Limoeiro do Norte (CE), 2013.

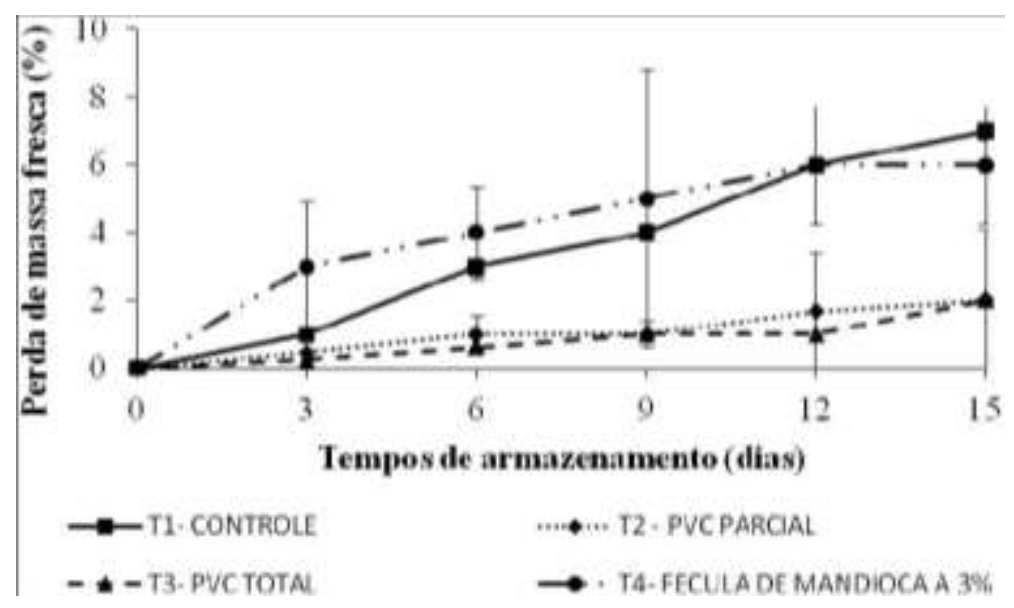

Fonte: Autores.

Os tratamentos T2 (PVC em tempo parcial) e T3 (PVC em tempo total) apresentaram menores perdas de massa. Conforme Silva et al. (2009) esses teores mais baixos são decorrência da barreira contra a movimentação de vapor de água que é estabelecida por meio do filme plástico que ao ser utilizado na conservação pós-colheita de frutos e hortaliças retém a umidade relativa no interior da embalagem, retardando desta forma o amadurecimento e a elevação das taxas respiratórias pela diminuição do etileno e atrasando o amolecimento (perda de firmeza) e várias outras transformações fisiológicas e bioquímicas.

Comparando-se os tratamentos com o uso do filme plástico com os frutos imersos em fécula de mandioca a $3 \%$ e os frutos controle observou-se que o filme plástico se mostrou mais adequado ao uso com relação a diminuição da perda de massa. Segundo Chitarra e Chitarra (2005), o uso de coberturas hidrofílicas, como o amido, tem limitações quanto às propriedades de barreira de vapor d'água.

Silva et al. (2009) avaliando a utilização de embalagem e refrigeração na conservação de atemoia cultivar 'Gefner' observaram perdas médias de massa de 7,8\% para frutos armazenados 15 dias sem embalagem, 2,5\% para frutos armazenados em bandeja recobertas com filme de PVC e 1,7\% para frutos embalados individualmente em filme de PVC.

\section{- Firmeza da polpa}

Observou-se perda de firmeza da polpa durante o período de armazenamento para todos os tratamentos estudados (Figura 2) com valores médios variando de 129,0 a 8,62N no início e aos 15 dias de armazenamento, respectivamente. 
Figura 2. Firmeza da polpa $(\mathrm{N})$ em frutos de atemoia 'Gefner' submetidos a diferentes tipos de recobrimento armazenados a $15 \pm 4^{\circ} \mathrm{C}$ e $85 \pm 4 \%$ de Umidade Relativa durante 15 dias. IFCE, Limoeiro do Norte (CE), 2013.

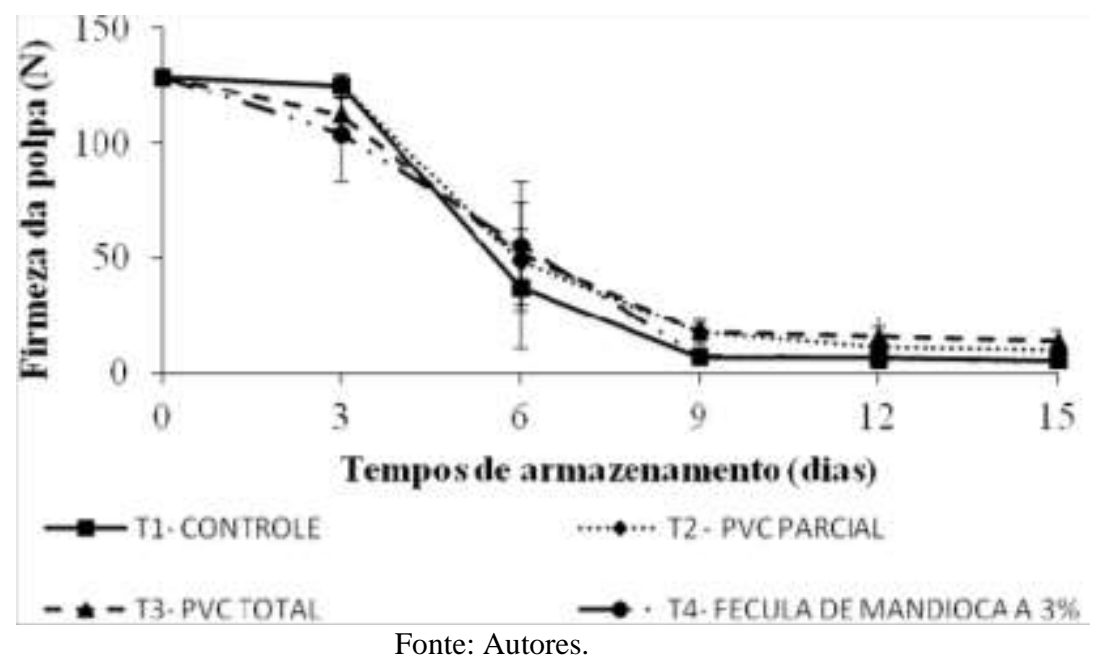

Com relação aos tipos de recobrimento, verificou-se que apesar de não existir diferença significativa entre os tratamentos estudados, os frutos dos tratamentos T2 (PVC em tempo parcial) e o tratamento T3 (PVC em tempo total) apresentaram tendência de maiores valores médios finais de firmeza da polpa, sendo de 9,45 e 13,3 N, respectivamente. Esse resultado concorda com os resultados encontrados para a característica perda de massa, pois os frutos recobertos com filme de PVC mantiveram-se com menor perda de massa o que auxilia na manutenção da firmeza dos frutos. Os frutos controle e imersos em fécula de mandioca a 3\% apresentaram menores valores médios finais e semelhantes sendo de 5,29 e 5,3N, respectivamente.

Conforme Dússan-Sarria (2003) o fruto de atemoia se torna macio devido à ação de enzimas que atuam na hidrólise do amido, na transformação dos constituintes celulósicos, bem como na conversão da protopectina em pectina solúvel.

\section{- Aparência externa}

Verificou-se que os valores de aparência externa apresentaram decréscimo durante o período de armazenamento dos frutos (Figura 3).

Figura 3. Aparência externa em frutos de atemoia 'Gefner' submetidos a diferentes tipos de recobrimentos e armazenados a 15 $\pm 4^{\circ} \mathrm{C}$ e $85 \pm 4 \%$ de Umidade Relativa durante 15 dias. IFCE, Limoeiro do Norte (CE), 2013.

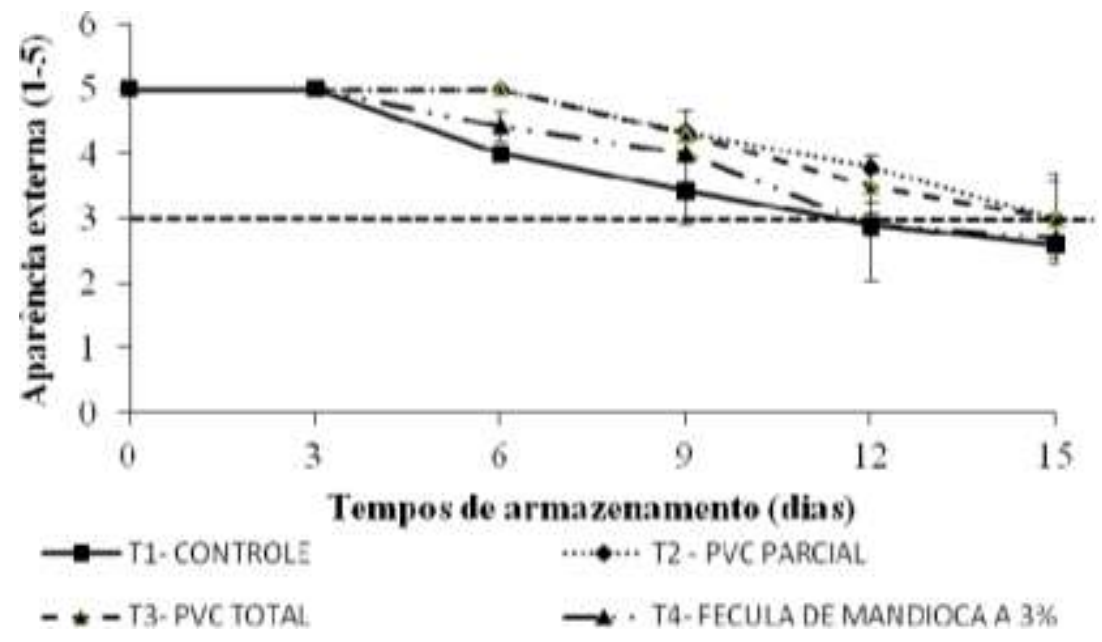

Fonte: Autores. 
Ao longo do período de armazenamento houve perda de qualidade externa ocasionada, principalmente, pelo escurecimento da casca, surgimento de rachaduras e ataque fúngico. A aparência externa é influenciada principalmente pela perda de água que ocorre durante os processos fisiológicos de transpiração e respiração dos frutos.

Durante o armazenamento, os frutos apresentaram redução de qualidade externa com valor médio de 2,85 no último dia. Desse modo, apresentando características impróprias de qualidade externa para ser destinado a comercialização. As Figuras 4 a 8 ilustram a aparência externa dos frutos de atemoia 'Gefner' durante o período de armazenamento refrigerado em atmosfera modificada.

Figura 4. Aparência externa dos frutos de atemoia 'Gefner' no $3^{\circ}$ dia de armazenamento a $15 \pm 4^{\circ} \mathrm{C}$ e $85 \pm 4 \%$ de Umidade Relativa durante 15 dias. IFCE, Limoeiro do Norte-CE, 2013. T1 (Controle), T2 (PVC em tempo parcial), T3 (PVC total) e T4 (Biofilme de fécula de mandioca a 3\%).
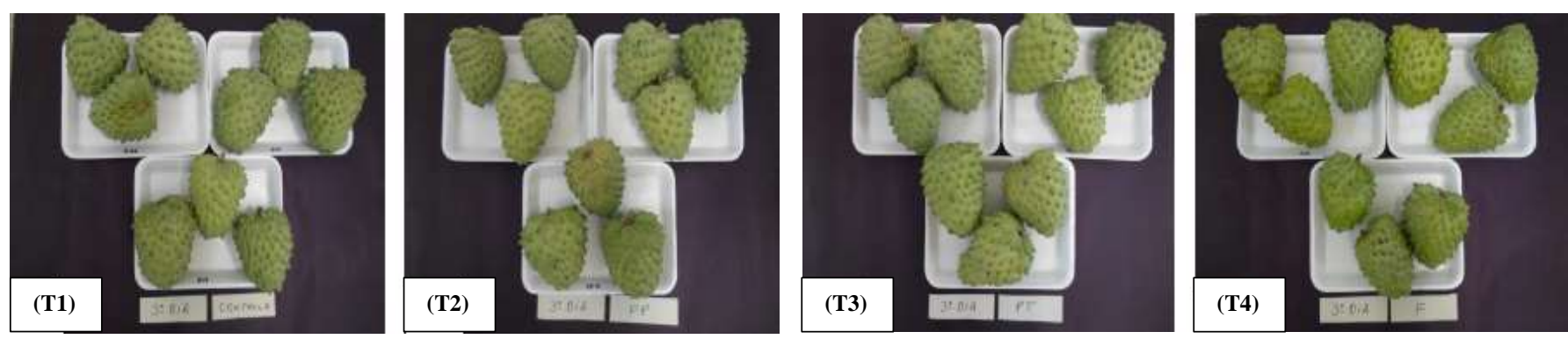

Fonte: Arquivo pessoal.

Ao $6^{\circ}$ dia de armazenamento (Figura 5) os frutos de atemoia encontravam-se em estado de maturação avançado quando comparados aos frutos do $3^{\circ}$ dia de armazenamento. Fato este verificado pela modificação da firmeza da polpa e aroma característico exalado durante o corte principalmente para os frutos controle (T1).

Figura 5. Aparência externa dos frutos de atemoia 'Gefner' no $6^{\circ}$ dia de armazenamento a $15 \pm 4^{\circ} \mathrm{C}$ e $85 \pm 4 \%$ de Umidade Relativa durante 15 dias. IFCE, Limoeiro do Norte-CE, 2013. T1 (Controle), T2 (PVC em tempo parcial), T3 (PVC total) e T4 (Biofilme de fécula de mandioca a $3 \%$ ).
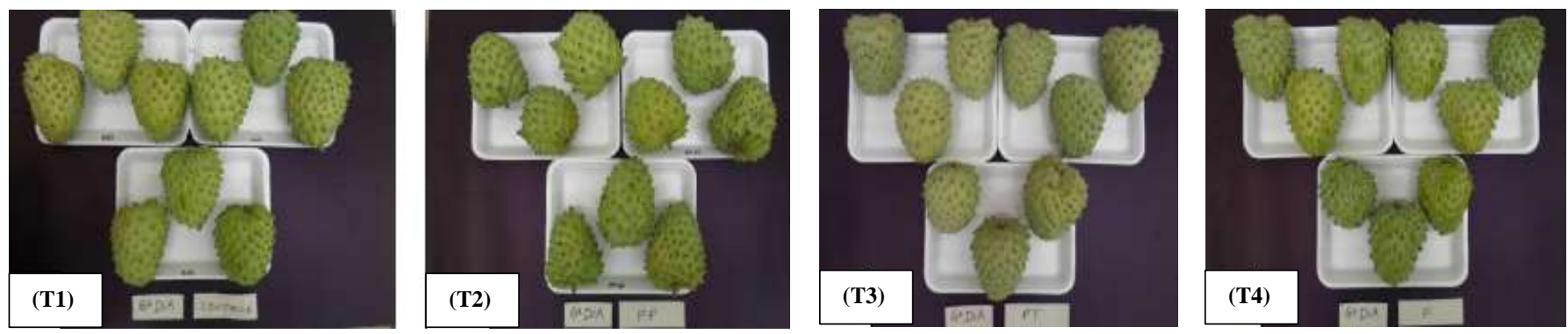

Fonte: Arquivo pessoal.

No $9^{\circ}$ dia de armazenamento (Figura 6) não foram observadas alterações na aparência externa dos frutos para todos os tratamentos, exceto os frutos recobertos com fécula de mandioca a 3\% que demonstraram desprendimento do biofilme aplicado. O tratamento T3 (polietileno total) apresentou frutos com melhor aspecto de cor da casca, demonstrando menor opacidade e frutos mais íntegros. Além disso, todos os frutos apresentaram odor agradável durante o corte, aptos ao consumo e comercialização até $9^{\circ}$ dia de armazenamento. A partir deste tempo ( $9^{\circ}$ dia), os frutos de todos os tratamentos apresentaram rachaduras e exposição da polpa branca ou creaming. Observou-se ainda que o surgimento das rachaduras iniciava-se da região próxima ao pedúnculo dos frutos. 
Figura 6. Aparência externa dos frutos de atemoia 'Gefner' no $9^{\circ}$ dia de armazenamento a $15 \pm 4^{\circ} \mathrm{C}$ e $85 \pm 4 \%$ de Umidade Relativa durante 15 dias. IFCE, Limoeiro do Norte-CE, 2013. T1 (Controle), T2 (PVC em tempo parcial), T3 (PVC total) e T4 (Biofilme de fécula de mandioca a $3 \%$ ).
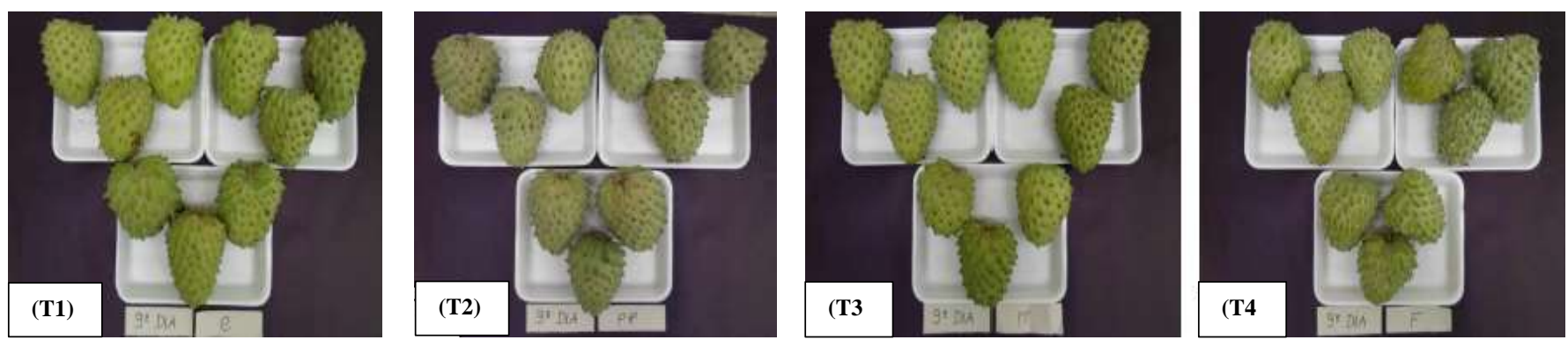

Fonte: Arquivo pessoal.

No $12^{\circ}$ dia de armazenamento (Figura 7) verificou-se a presença de rachaduras e escurecimento da casca dos frutos principalmente os pertencentes ao tratamento T4 (fécula de mandioca a 3\%). Os tratamentos T2 (polietileno em tempo parcial), T1 (frutos controle) e T3 (polietileno em tempo total) demonstraram escurecimento da casca e polpa mole. Frutos controle demonstraram menor intensidade de escurecimento da casca. Essas modificações observadas nos frutos pertencentes aos demais tratamentos comprometem o aspecto e, portanto, a qualidade, aceitação e consequentemente a comercialização dos frutos pelos consumidores. Além disso, ainda apresentavam dificuldade para manuseio durante as avaliações pelo fato da fácil desintegração, perda considerável da firmeza e odor desagradável comprometendo-os para comercialização.

Salvador et al. (2018) estudando a qualidade pós- colheita de Pinha refrigeradas e armazenadas em embalagens de papelão cobertas com filme de PVC verificaram que as menores temperaturas não afetaram as características físico-químicas dos frutos, mas aumentaram o tempo de armazenamento em três dias. O uso da embalagem de PVC favoreceu a manutenção do peso dos frutos e aparência externa e interna reduzindo o teor de sólidos solúveis na polpa.

Figura 7. Aparência externa dos frutos de atemoia 'Gefner' no $12^{\circ}$ dia armazenamento a $15 \pm 4{ }^{\circ} \mathrm{C}$ e $85 \pm 4 \%$ de Umidade Relativa durante 15 dias. IFCE, Limoeiro do Norte-CE, 2013. T1 (Controle), T2 (PVC em tempo parcial), T3 (PVC total) e T4 (Biofilme de fécula de mandioca a 3\%).
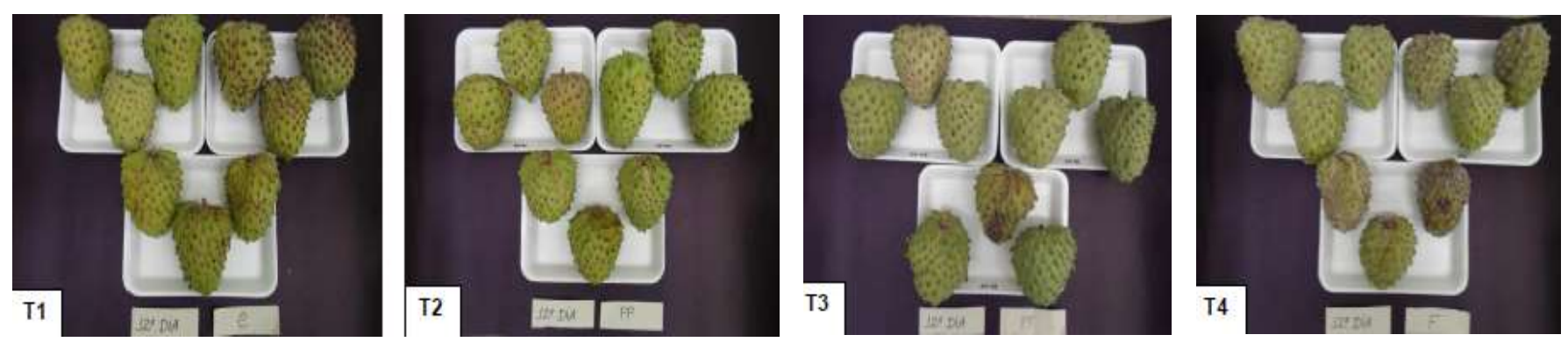

Fonte: Arquivo pessoal.

Com relação aos frutos do $15^{\circ}$ dia de armazenamento (Figura 8) observou-se que estes se apresentaram com maior número de manchas escuras na casca, desprendimento do biofilme de fécula de mandioca, aparecimento de coloração laranja na polpa e rachaduras severas junto ao pedúnculo e na extensão da região lateral da casca. Verificou-se que os frutos estavam com polpa bastante mole evidenciando estádio de maturação avançado. $\mathrm{O}$ ataque fúngico foi verificado com maior intensidade nos tratamentos T3 (PVC em tempo total) e T4 (fécula de mandioca a 3\%). 
Figura 8. Aparência externa dos frutos de atemoia 'Gefner' no $15^{\circ}$ dia armazenamento a $15 \pm 4{ }^{\circ} \mathrm{C}$ e $85 \pm 4 \%$ de Umidade Relativa durante 15 dias. IFCE, Limoeiro do Norte-CE, 2013. T1 (Controle), T2 (PVC em tempo parcial), T3 (PVC total) e T4 (Biofilme de fécula de mandioca a $3 \%$ ).
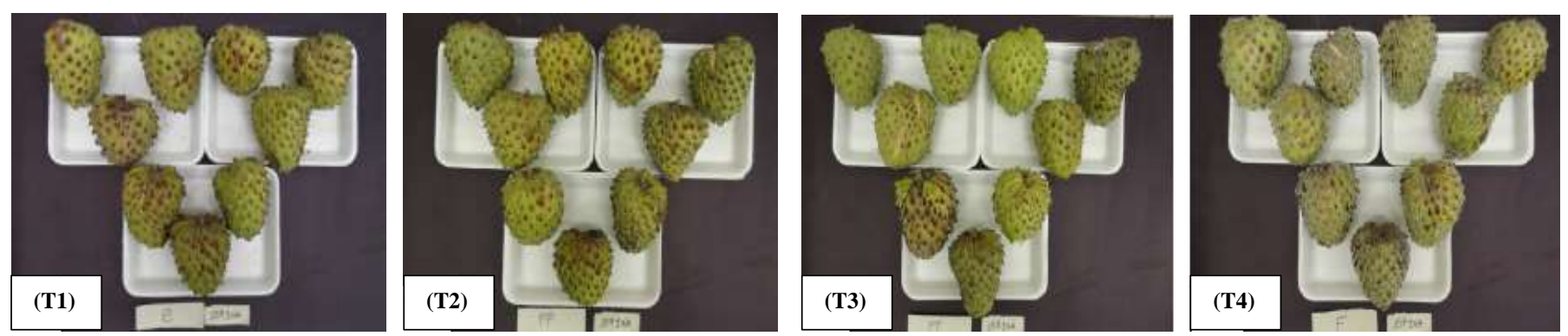

Fonte: Arquivo pessoal.

Torres (2008) avaliando a qualidade pós-colheita de atemoias 'Thompson' armazenadas sob atmosfera modificada e associada ao uso de tratamento hidrotérmico observou que o tratamento hidrotérmico não teve influência sobre o tempo de armazenamento de frutos de atemoia desses frutos, no entanto, a embalagem contribuiu para a manutenção da aparência externa durante o período total do armazenamento de atemoias 'Thompson' nas temperaturas de 8 e $15{ }^{\circ} \mathrm{C}$, por 21 e 18 dias, respectivamente. A aparência externa é um dos principais parâmetros utilizados pelos consumidores no momento da compra de frutos.

\section{- Cor da casca}

Ao longo do armazenamento dos frutos de atemoia 'Gefner' verificou-se pequeno decréscimo nos valores do ${ }^{\circ}$ hue ou ângulo de cor (Figura 9). Essa alteração indica variação de cor da casca de verde para verde amarelado, fato observado em todos os tratamentos, sendo mais intenso para os frutos recobertos com fécula de mandioca a 3\% (T2) apresentando valores finais de $75,19^{\circ}$ hue.

Figura 9. Ângulo hue ( ${ }^{\circ}$ hue) da casca de frutos de atemoia 'Gefner' submetidos a diferentes tipos de recobrimentos e armazenados a $15 \pm 4^{\circ} \mathrm{C}$ e $85 \pm 4 \%$ de Umidade relativa durante 15 dias. IFCE, Limoeiro do Norte (CE), 2013.

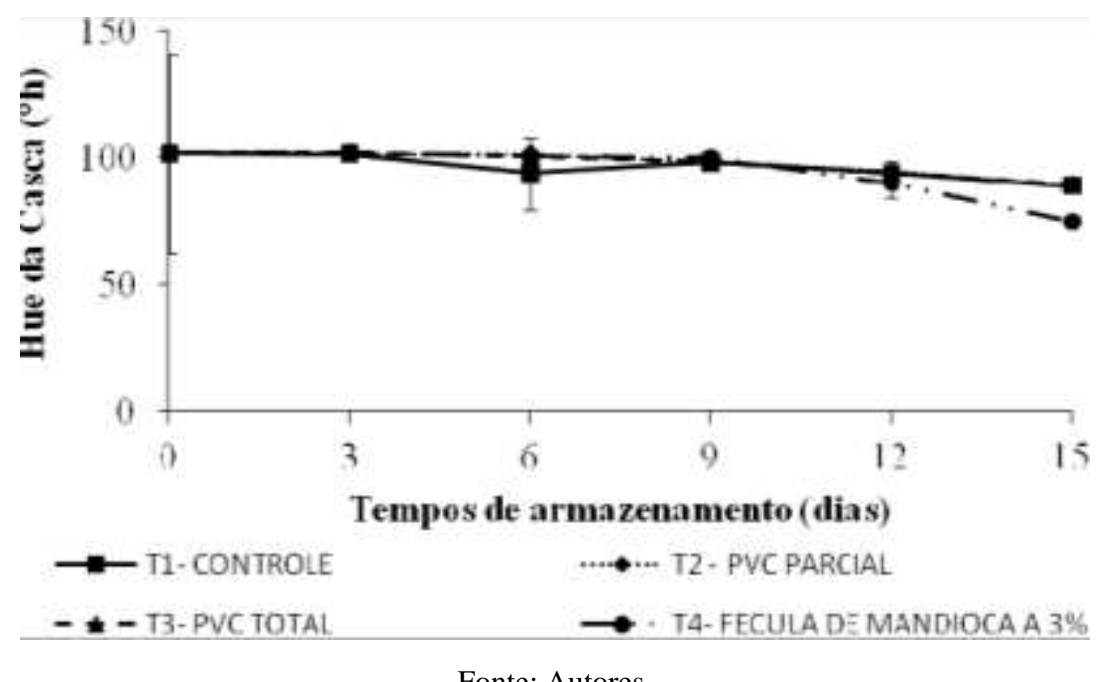

Fonte: Autores. 
O decréscimo no ângulo hue ao longo do período de armazenamento indica a mudança de coloração na casca dos frutos de verde para verde amarelado. O resultado observado no presente trabalho concorda com os resultados obtidos por Lima et al. (2003) que citam que essa alteração deve estar associada à degradação da clorofila.

Os frutos totalmente revestidos com PVC e os frutos controle apresentaram valores mais elevados de ângulo de cor sendo de 94,44 C e 93,95, respectivamente. Frutos revestidos parcialmente demonstraram médias finais de 88,92 C. A diferença nos valores de cromaticidade ou intensidade de cor pode ser explicada pelo fato de que o uso de revestimento de PVC em tempo parcial, contribuiu positivamente para retardar o amadurecimento dos frutos, e consequentemente, o desenvolvimento da coloração da casca das atemoias, reação esta, que ocorre em decorrência da perda de clorofila.

De acordo com Siqueira (2008) a utilização da atmosfera modificada leva a um atraso no desmascaramento dos carotenóides pré-existentes, em função da lenta degradação da clorofila a partir da atividade enzimática da clorofilase deixando os frutos mais verdes por mais tempo. Esse comportamento pode ser explicado pelo fato de que o recobrimento reduz a concentração de oxigênio que o fruto necessita para realizar seu metabolismo normal. Porém, no presente trabalho não foi observado diferença significativa entre os frutos recobertos com filme de PVC e o controle apesar dos frutos controle terem demonstrando menor valor médio final para essa variável.

A intensidade da cor (croma ou cromaticidade) apresentou aumento dos valores até o $6^{\circ}$ dia de armazenamento com posterior redução (Figura 10). Os frutos revestidos com fécula de mandioca a 3\% (T4) apresentaram o menor valor de cromaticidade ao final do armazenamento apresentando valor médio de 75,19 C, provavelmente devido ao aspecto final do recobrimento que estava se desprendendo da casca.

Figura 10. Cromaticidade da casca de frutos de atemoia 'Gefner' submetidos a diferentes tipos de recobrimentos e armazenados a $15 \pm 4^{\circ} \mathrm{C}$ e $85 \pm 4 \%$ de Umidade relativa durante 15 dias. IFCE, Limoeiro do Norte (CE), 2013.

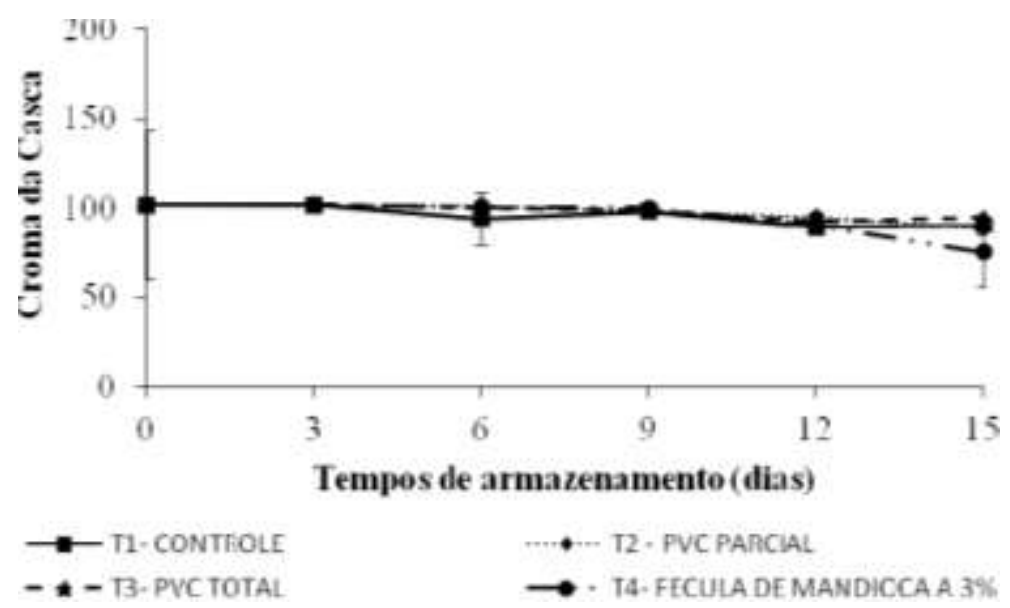

Fonte: Autores.

Os valores de luminosidade (brilho) sofreram pequenas alterações durante o armazenamento das atemoias (Figura 11) apresentando leve redução após o $12^{\circ}$ dia de armazenamento, sendo mais intensa para os frutos controle, possivelmente associada ao início do escurecimento da casca decorrente do avanço do amadurecimento e posterior senescência da atemoia. 
Figura 11. Luminosidade da casca de frutos de atemoia Gefner submetidos a diferentes tipos de recobrimentos e armazenados a $15 \pm 4^{\circ} \mathrm{C}$ e $85 \pm 4 \%$ de Umidade relativa durante 15 dias. IFCE, Limoeiro do Norte (CE), 2013.

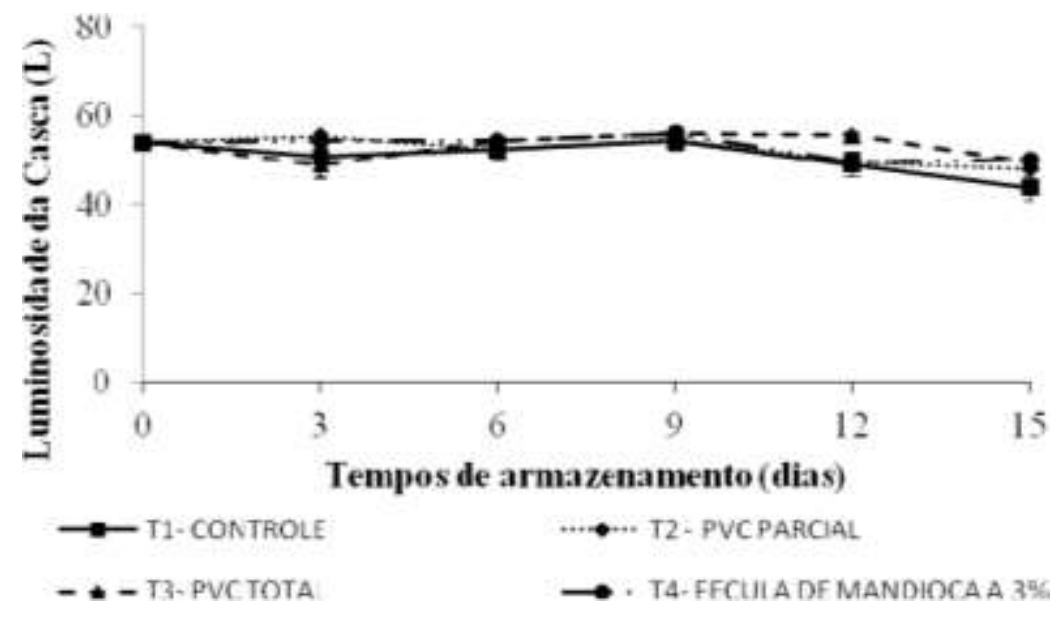

Fonte: Autores.

Farias et al. (2011) afirmaram que no amadurecimento de anonáceas entre outras modificações a cor da casca perde o brilho sendo que este fenômeno está associado ao aumento do pico respiratório e de etileno. De acordo com os autores, os frutos acondicionados em atmosfera modificada mudaram de cor mais lentamente, não apresentando diferença significativa entre os tratamentos e os dias de armazenamento, sendo que os frutos sem embalagem atingiram, em um menor período, menores valores do ângulo hue. Esse comportamento pode ser explicado pelo fato de que a embalagem, quando em concentrações ideais de gás carbônico e oxigênio, diminui a velocidade do metabolismo do fruto, atrasando o desmascaramento dos carotenoides préexistentes, em função da lenta degradação da clorofila a partir da atividade enzimática da clorofilase.

- Índice de rachadura

Observou-se aumento da incidência de frutos rachados durante o armazenamento dos frutos de atemoias para todos os tratamentos estudados (Figura 12). Os frutos do controle apresentaram rachaduras apenas em um fruto ao $3^{\circ}$ dia de armazenamento, enquanto que os demais tratamentos só apresentaram frutos rachados no $6^{\circ}$ dia de armazenamento. Verificouse ainda que os frutos recobertos parcialmente com PVC apresentaram os maiores índices de rachadura no $6^{\circ}$ dia de armazenamento com 7 frutos rachados, enquanto que os demais tratamentos apresentaram rachaduras em apenas 3 frutos. 
Figura 12. Índice de rachaduras (\%) em frutos de atemoia 'Gefner' submetidos a diferentes tipos de recobrimentos e armazenados a $15 \pm 4^{\circ} \mathrm{C}$ e $85 \pm 4 \%$ de Umidade relativa durante 15 dias. IFCE, Limoeiro do Norte (CE), 2013.

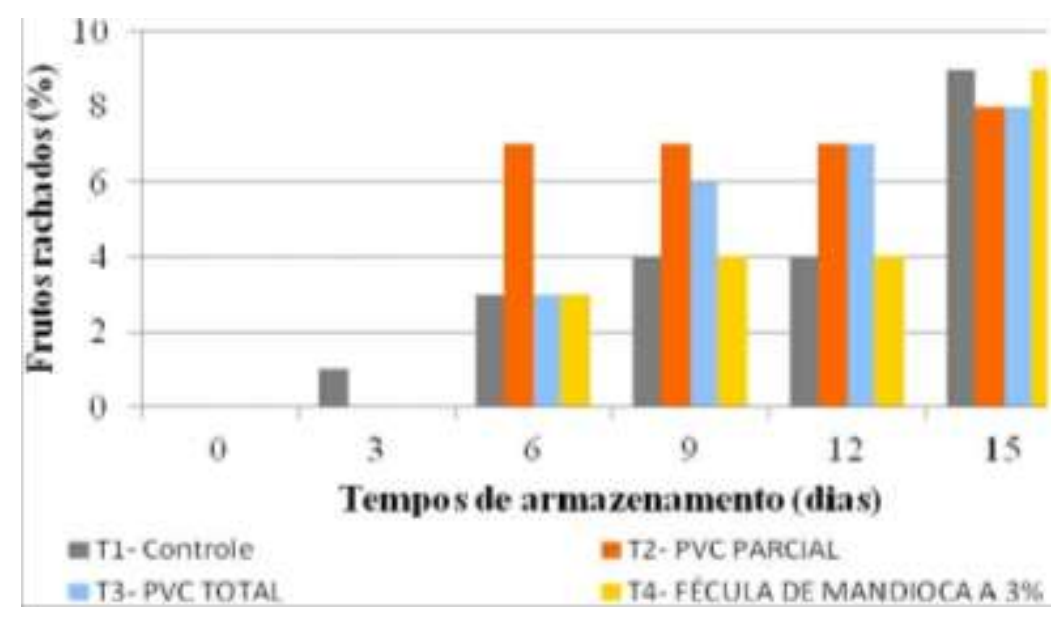

Fonte: Autores.

Observou-se que no início do experimento os frutos controle (T1) apresentaram 1 fruto rachado. Frutos envoltos com PVC em tempo parcial (T2) demonstraram rachaduras em 7 frutos no $6^{\circ}, 9^{\circ}$ e $12^{\circ}$ dias de armazenamento. No $12^{\circ}$ dia frutos envoltos com PVC em tempo total apresentaram 7 sete frutos rachados. No $9^{\circ}$ e $12^{\circ}$ dias de armazenamento frutos envoltos em fécula de mandioca a $3 \%$ demonstraram três e quatro frutos rachados nesse período. Ao final do armazenamento os frutos envoltos em embalagem plástica de PVC demonstraram as menores contagens de rachaduras quando comparados aos frutos controle e envoltos em fécula de mandioca a $3 \%$.

Reges et al. (2018) avaliando a qualidade pós-colheita de ata (Annona squamosa L.) submetida ao atraso na retirada do filme de PVC observaram que os frutos do tratamento controle apresentaram menor incidência de rachaduras associado ao fato de que a embalagem retardou o amadurecimento dos frutos sem comprometer a qualidade. Segundo os autores o filme de PVC retardou a perda de massa, diminuiu a acidez titulável e contribuiu positivamente para a aparência externa e vida pós-colheita de 6 dias. Os frutos que tiveram a retirada do filme de PVC no 4 e $6^{\circ}$ dias de armazenamento demonstraram maior firmeza.

\section{2 Características físico-químicas}

- Acidez Total Titulável

Observou-se aumento nos teores de acidez titulável até o $12^{\circ}$ dia de armazenamento com posterior decréscimo para todos os tratamentos estudados (Figura 13). Os frutos embalados em tempo total com embalagem de PVC (T3) ou em tempo parcial (T2), apresentaram os menores teores de acidez titulável. Os frutos controle (T1) atingiram teores mais elevados no $3^{\circ}$ dia de armazenamento. Os frutos recobertos com fécula de mandioca a 3\% (T4) demonstraram atraso na elevação dos teores de acidez, mas, ao final do armazenamento, obtiveram teores próximos aos observados nos frutos controle. 
Figura 13. Acidez Total Titulável (\%) de ácido málico em frutos de atemoia 'Gefner' submetidos a diferentes tipos de recobrimentos e armazenados a $15 \pm 4^{\circ} \mathrm{C}$ e $85 \pm 4 \%$ de Umidade relativa durante 15 dias. IFCE, Limoeiro do Norte (CE), 2013 .

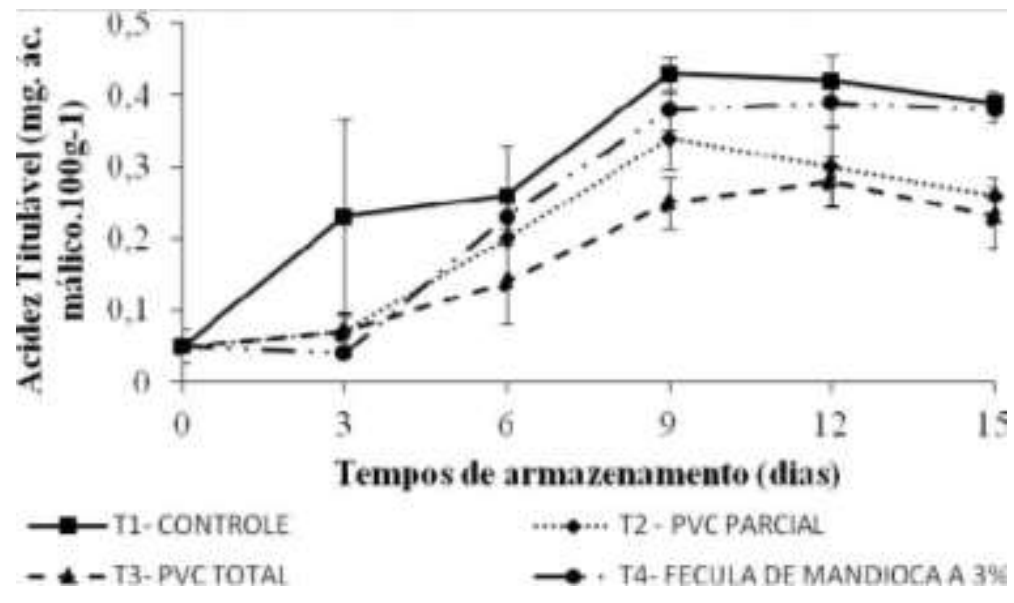

Fonte: Autores.

Os menores teores de ácidos encontrados nos frutos recobertos com PVC possivelmente devem-se a redução no metabolismo dos mesmos pela redução na concentração de $\mathrm{O} 2$ causado pela barreira do filme de PVC.

Silva et al. (2011) avaliando a qualidade de pinhas armazenadas a $15^{\circ} \mathrm{C}$ envoltas ou não por embalagem de polietileno de baixa densidade (PEBD), constataram tendência de diminuição nos valores de acidez titulável durante o armazenamento.

\section{- $\mathrm{pH}$}

Observou-se que o pH (Figura 14), demonstrou diminuição dos valores para todos os tratamentos, sendo menos intensa para os frutos recobertos totalmente com PVC (T3) que apresentou valor médio final de 5,02. Frutos controle (T1), revestidos com fécula de mandioca a 3\% (T4), e envoltos parcialmente em PVC (T2) obtiveram valores muito semelhantes de pH variando de 4,70 a 4,74 .

Figura 14. Evolução do pH em frutos de atemoia 'Gefner' submetidos a diferentes tipos de recobrimentos e armazenados a 15 $\pm 4^{\circ} \mathrm{C}$ e $85 \pm 4 \%$ de Umidade relativa durante 15 dias. IFCE, Limoeiro do Norte (CE), 2013.

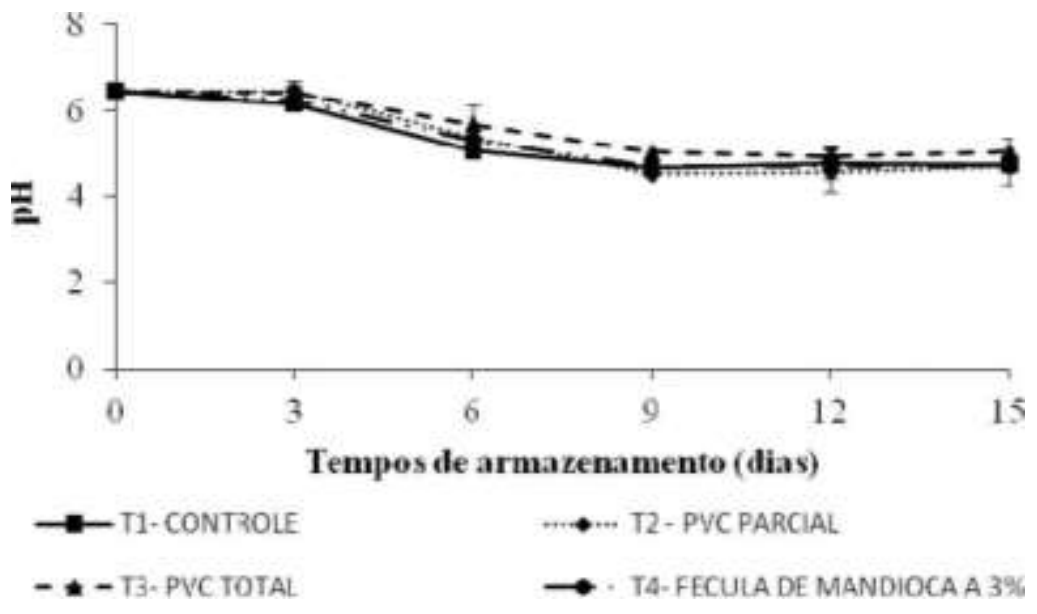

Fonte: Autores. 
Conforme Silva et al. (2009) esse comportamento deve-se ao efeito do recobrimento com PVC que diminui o contato do fruto com a atmosfera e, como consequência, retarda as transformações bioquímicas responsáveis pelas alterações no pH dos frutos.

Silva e Muniz (2011) avaliando a qualidade pós-colheita de atemoias 'Gefner' em estádios de maturação “de vez” e "maduro" verificaram valores médios de $\mathrm{pH}$ de 4,33 e 4,29, respectivamente, estando de acordo aos valores encontrados no presente trabalho.

\section{- Sólidos Solúveis}

Os teores de sólidos solúveis apresentaram aumento durante o armazenamento com valor inicial de $3,75^{\circ}$ Brix e posteriormente atingindo teor médio final de $16,0^{\circ}$ Brix (Figura 15).

Figura 15. Teor de sólidos solúveis ( ${ }^{\circ}$ Brix) em frutos de atemoia 'Gefner' submetidos a diferentes tipos de recobrimentos e armazenados a $15 \pm 4^{\circ} \mathrm{C}$ e $85 \pm 4 \%$ de Umidade relativa durante 15 dias. IFCE, Limoeiro do Norte (CE), 2013.

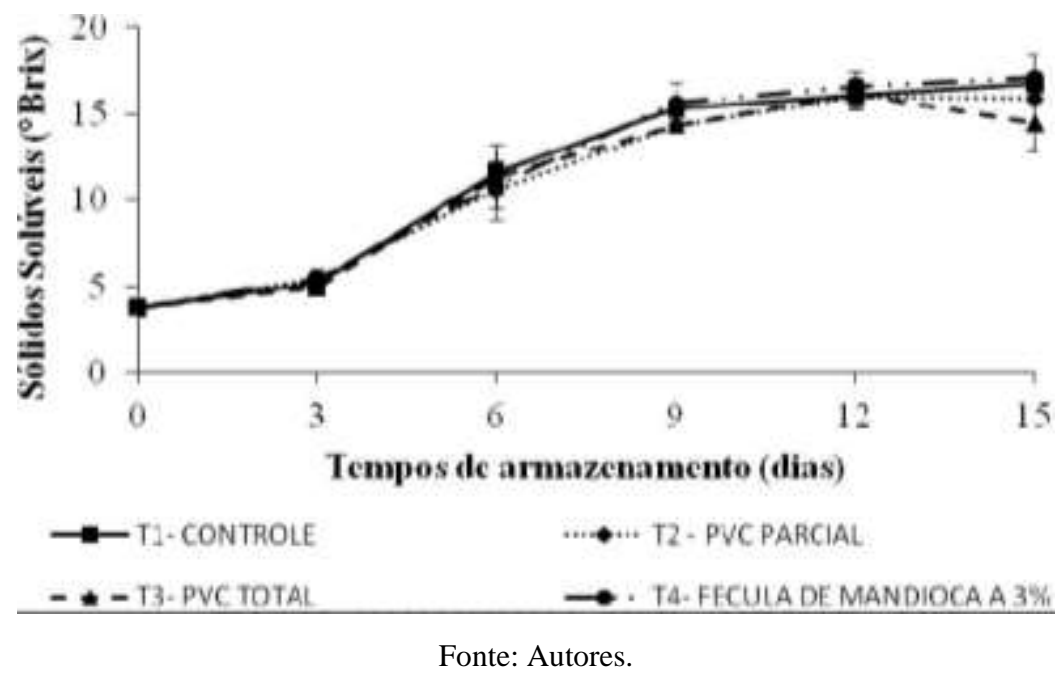

Esse aumento nos teores de sólidos solúveis está relacionado à hidrólise do amido e consequente acúmulo de açúcares solúveis como glicose e frutose. Desse modo, o incremento nos teores de sólidos solúveis em atemoias ocorre devido, provavelmente, à conversão do amido em açúcares solúveis (Silva et al., 2009).

Os frutos revestidos com filme de PVC apresentaram, em média, os menores teores de sólidos solúveis. Esse comportamento pode estar relacionado ao uso da embalagem de PVC que retardou o processo de amadurecimento do fruto com consequente diminuição da hidrólise do amido e posterior transformação em açúcares solúveis. Os filmes plásticos à base de polietileno ou cloreto de polivinila (PVC), devido a sua praticidade, ao custo relativamente baixo e à alta eficiência tem sido bastante utilizados, principalmente quando associados ao armazenamento refrigerado para evitar perdas de frutos (Silva et al., 2009).

Silva et al. (2011) avaliando o armazenamento pós-colheita de pinhas armazenadas em diferentes embalagens e temperatura ambiente e refrigerada constataram os frutos armazenados em temperatura ambiente apresentaram no $9^{\circ}$ dia de armazenamento apresentaram teor de $26^{\circ}$ Brix, enquanto que os frutos embalados em PVC em temperatura de refrigeração apresentaram no $15^{\circ}$ dia valores de sólidos solúveis próximos a $20{ }^{\circ}$ Brix, demonstrando uma redução no processo de amadurecimento. 
- Amido

Evidenciou-se com o decorrer do armazenamento o decréscimo acentuado do teor de amido para todos os tratamentos estudados (Figura 16). Entretanto, os frutos revestidos em biofilme de fécula de mandioca a 3\% e os frutos controle mostraram hidrólise do amido mais acelerada, fato este comprovado pelos menores valores médios finais observados de 2,94 e 1,43\% de amido, respectivamente. Frutos revestidos parcial e totalmente com filme de PVC demonstraram médias finais de 3,37 e 4,94\% de amido, respectivamente.

Figura 16. Teor de amido (\%) de frutos de atemoia 'Gefner' submetidos a diferentes tipos de recobrimentos e armazenados a $15 \pm 4^{\circ} \mathrm{C}$ e $85 \pm 4 \%$ de Umidade relativa durante 15 dias. IFCE, Limoeiro do Norte (CE), 2013.

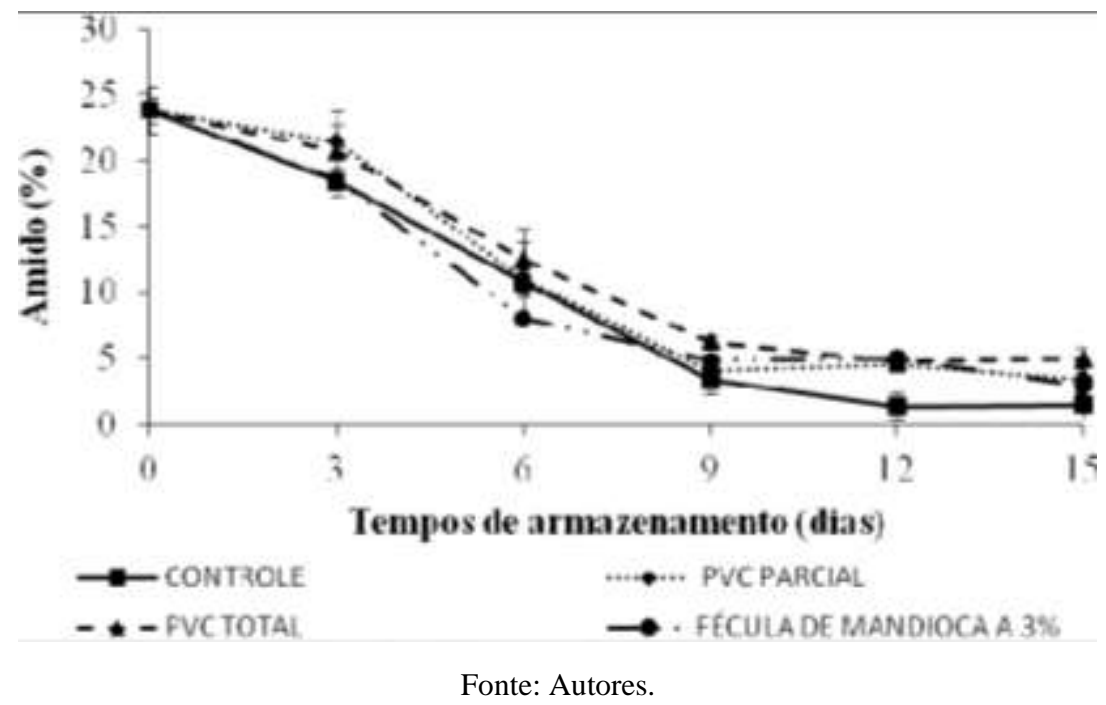

Essa redução do conteúdo de amido está intimamente associada à hidrólise desse carboidrato ocasionada pela ação de enzimas específicas (amilases) que degradam a extensa cadeia do amido dando origem aos açúcares solúveis tais como glicose. As características amido e açúcares totais apresentam comportamento inversamente proporcional, pois à medida que o teor de amido diminui, a porcentagem de açúcares solúveis totais aumenta.

Aguiar (2010) caracterizando atemoias 'Gefner' em três estádios de maturação (90, 120 e 128 dias) verificou uma redução no conteúdo de amido ao longo do amadurecimento dos frutos com valores de 25,15 e $2,5 \%$, respectivamente.

Teores de 0,4 e $0,8 \%$ de amido foram obtidos em atemoias 'Gefner' colhidas em estado de maturação fisiológica e permaneceram armazenadas a $25,9 \pm 1,7{ }^{\circ} \mathrm{C}$ e umidade relativa $66 \pm 5 \%$ até atingirem o estádio de maturação maduro (Batista, 2010).

\section{- Açúcares totais}

Verificou-se aumento nos teores de açúcares totais no decorrer do período de armazenamento em todos os tratamentos (Figura 17). Assim, os frutos demonstraram aumento de açúcares totais apresentando médias finais de 15,03; 14,29; 15,03 e $15,35 \%$ para os tratamentos $\mathrm{T} 1, \mathrm{~T} 2, \mathrm{~T} 3$ e $\mathrm{T} 4$, respectivamente. 
Figura 17. Teor de açúcares totais (\%) de frutos de atemoia 'Gefner' submetidos a diferentes tipos de recobrimentos e armazenados a $15 \pm 4^{\circ} \mathrm{C}$ e $85 \pm 4 \%$ de Umidade relativa durante 15 dias. IFCE, Limoeiro do Norte (CE), 2013.

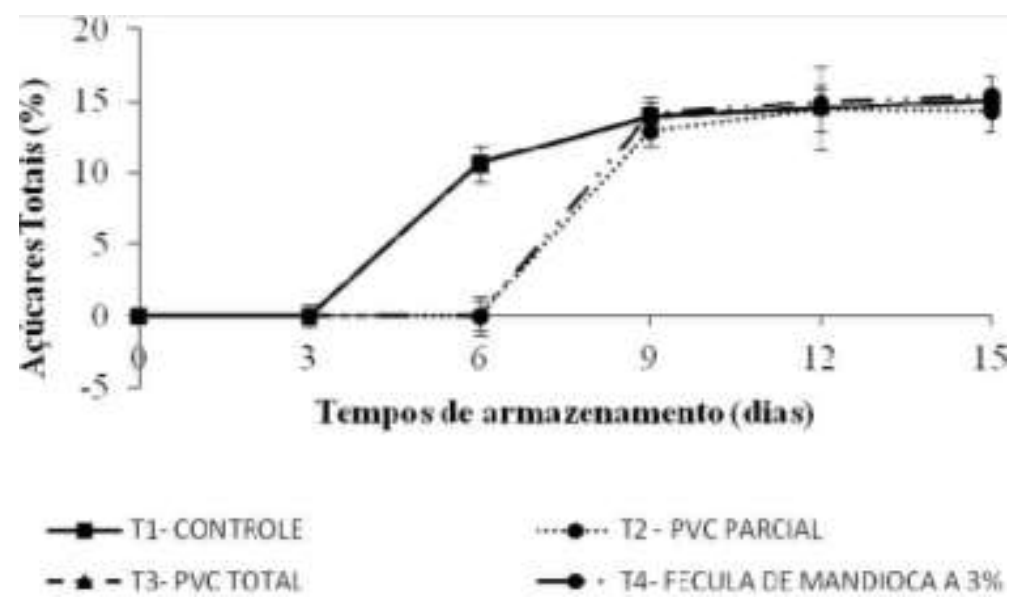

Fonte: Autores.

O aumento do teor de açúcares totais é decorrente da hidrólise do amido que fornece como produto de sua degradação açúcares solúveis como a glicose. O fornecimento destes açúcares influencia diretamente o teor de sólidos solúveis (Figura 10) da polpa dos frutos visto que estes em sua maioria são compostos, principalmente, por açúcares, além de outras substâncias dissolvidas no suco celular como ácidos orgânicos e vitaminas. Assim, o aumento do teor de açúcares solúveis totais, pode ser causado devido à hidrólise do amido, desidratação dos frutos e degradação de polissacarídeos da parede celular.

O teor de sólidos solúveis totais apresenta alta correlação positiva com o teor de açúcares e, portanto, geralmente, é aceito como uma importante característica de qualidade (Aguiar, 2018).

- Ratio

Observou-se durante o período de armazenamento redução da variável ratio para os todos os tratamentos (Figura 18). Porém, os frutos revestidos totalmente em filme de PVC apresentaram maior valor de ratio (60,53), enquanto que o menor valor médio final foi verificado para os frutos do controle (41,67). Frutos revestidos com biofilme de fécula de mandioca a 3\% e parcialmente revestidos em filme de PVC demonstraram valor médio de 58,77. 
Figura 18. Relação sólidos solúveis e acidez titulável (SS/AT) de frutos de atemoia 'Gefner' submetidos a diferentes tipos de recobrimentos armazenados a $15 \pm 4{ }^{\circ} \mathrm{C}$ e $85 \pm 4 \%$ de Umidade relativa durante 15 dias. IFCE, Limoeiro do Norte (CE), 2013.

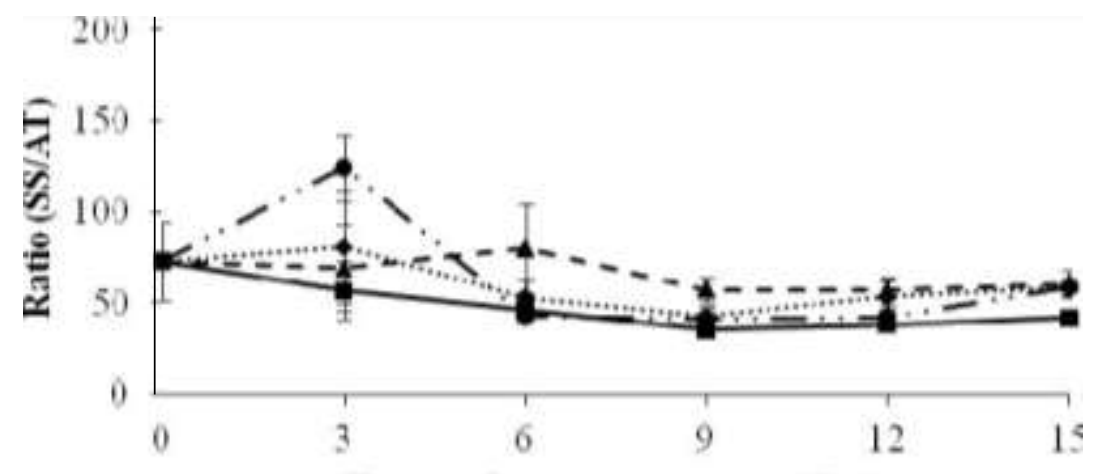

Tempos de armazenamento (dias)

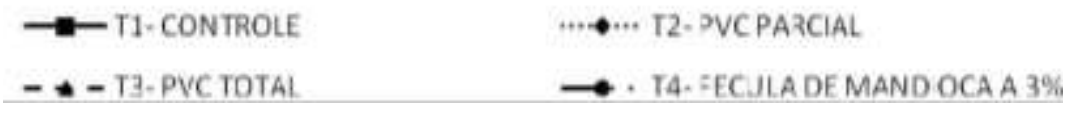

Fonte: Autores.

Verificou-se maiores valores de ratio no $3^{\circ}$ e $6^{\circ}$ dias de armazenamento nos frutos controle e revestidos com biofilme de fécula de mandioca a $3 \%$ com posterior redução ao final do armazenamento para todos os tratamentos.

A relação sólidos solúveis/acidez titulável é um índice representativo da medição isolada dos açúcares ou da acidez, pois expressa a proporção açúcar/ácido, que resulta no sabor apresentado pelo fruto (Chitarra; Chitarra, 2005).

O ratio ou relação sólidos solúveis e acidez (SS/AT) demonstra tendência ao aumento durante o amadurecimento, devido ao aumento no teor de sólidos solúveis e a diminuição na quantidade de ácidos orgânicos. Dessa forma, tanto fatores ambientais e fisiológicos que interferem no metabolismo dos açúcares e ácidos, estarão interferindo a relação SS/AT e consequentemente no sabor do fruto (Hojo et al., 2007). Araújo Neto et al. (2011) verificando o ponto de colheita de frutos de envira-caju obtiveram valores de ratio de 64,17 .

Aguiar (2010) caracterizando frutos de atemoia 'Gefner' observou que à medida que avança o estádio de maturação o conteúdo de sólidos solúveis e o ratio aumentam em atemoia. Os três estádios diferenciaram entre si. Aos 128 dias os frutos alcançaram o maior valor de ratio (55,00) em comparação com 25,00 e 32,06 para os estádios de 90 e 120 dias, respectivamente. Ainda no último estádio de maturação os frutos alcançaram os maiores valores de sólidos solúveis sendo de $32,33{ }^{\circ}$ Brix. Durante a caracterização dos frutos para os três estádios verificou-se aumento do valor do ratio de 25,00 para 55,00.

A seleção em direção ao aumento da relação SS/AT é desejável para a obtenção e aceitação de frutos para o consumo in natura, e portanto, a correlação de características é extremamente importante, pois permite avaliar quantitativamente a relevância de um caráter em relação a outro (Giles et al., 2016).

\section{- Vitamina C}

Observou-se que, durante o armazenamento dos frutos o teor de vitamina C variou em todos os tratamentos (Figura 19). Os frutos do controle e revestidos com biofilme de fécula de mandioca a 3\% apresentaram diferenças e variações quando comparados aos frutos revestidos parcial e totalmente em filme PVC durante o $9^{\circ}$ e $12^{\circ}$ dias de armazenamento. 
Figura 19. Teor de vitamina $\mathrm{C}$ (mg. ácido ascórbico. $100 \mathrm{~g}^{-1}$ ) em frutos de atemoia 'Gefner' submetidos a diferentes tipos de recobrimentos e armazenados a $15 \pm 4^{\circ} \mathrm{C}$ e $85 \pm 4 \%$ de Umidade relativa durante 15 dias. IFCE, Limoeiro do Norte (CE),2013.

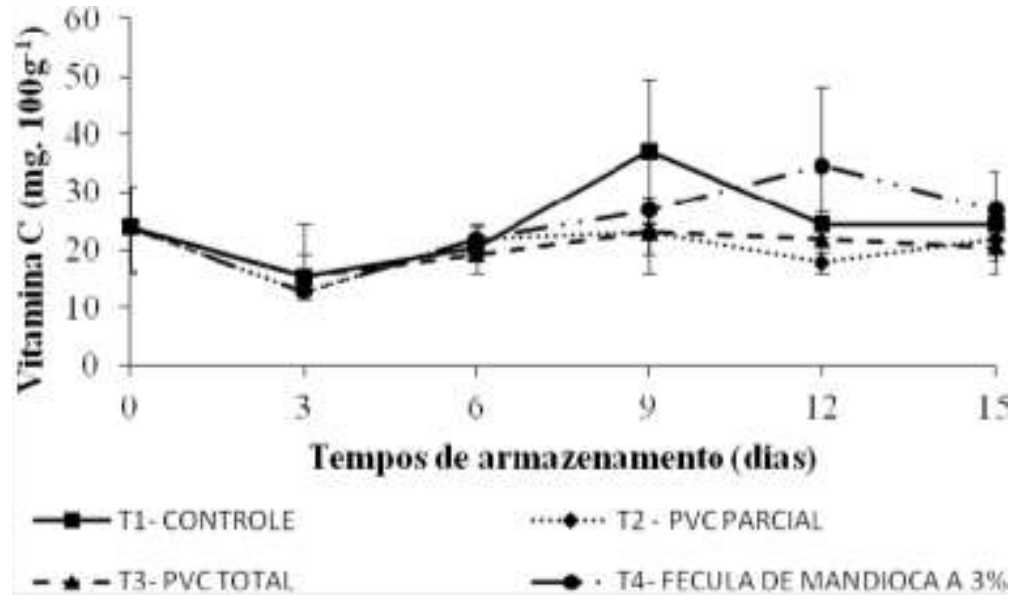

Fonte: Autores.

Os frutos revestidos parcial e totalmente com filme de PVC apresentaram valores médios finais inferiores $(21,79$ e 20,50 mg de ácido ascórbico, respectivamente) quando comparados aos frutos envoltos em fécula de mandioca a 3\% e os frutos controle que obtiveram valores médios de 24,35 e 26,91mg de ácido ascórbico, respectivamente (Figura 14). A presença do filme plástico, possivelmente, ocasionou alteração na síntese dessa vitamina por minimizar o processo de respiração.

\section{Conclusões}

A utilização do recobrimento parcial ou totalmente com PVC retardou a perda de massa nos frutos e aumentou os teores de acidez titulável, além de ter contribuído para melhor aparência externa e vida útil pós-colheita de 9 dias.

O uso do recobrimento com fécula de mandioca a 3\% não reduziu a perda de massa, ocasionou a perda de qualidade externa e atrasou as mudanças de coloração da casca juntamente com os outros recobrimentos. No entanto, foi eficiente em atrasar o início das rachaduras dos frutos.

Ao final do armazenamento todos os frutos apresentaram rachaduras, pois de forma inevitável, essa característica peculiar da fruta, não foi impedida pelo uso dos tratamentos empregados, considerando como fatores determinantes para tal evento, o metabolismo acelerado e o alto pico respiratório característicos da atemoia 'Gefner', pertencente à família das anonáceas.

Sugere-se como trabalhos futuros, análises de compostos bioativos, antioxidantes, atividade enzimática, potencial de toxicidade em frutos de anonáceas como a atemoia 'Gefner' em diferentes estádios de maturação, tendo em vista que são escassos os trabalhos com esses frutos, a fim de elucidar e investigar maiores parâmetros de qualidade assim como o entendimento mais robusto acerca da fisiologia pós-colheita.

\section{Agradecimentos}

Os autores agradecem ao Instituto Federal do Ceará, Campus Limoeiro do Norte-Ce, pelo apoio na realização dessa pesquisa.

Ao professor Dr. Pahlevi Augusto de Souza, pela confiança, apoio, amizade, dedicação e orientações primordiais.

E à Empresa Brasileira de Pesquisa Agropecuária - Embrapa Agroindústria Tropical, na cidade de Fortaleza- Ce, pela apoio técnico na realização de análises tão imprescindíveis para a elucidação e entendimento dessa pesquisa; conhecimentos 
adquiridos, assim como orientações e ensinamentos do Dr. e pesquisador desta instituição, Carlos Farley Hébster de Moura.

E ao professor Dr. Franciscleudo Bezerra Costa da Universidade Federal da Paraíba- UFPB Campus Pombal, que contribuiu com seus ensinamentos e conhecimentos.

\section{Referências}

Aguiar, A. L. L. Caracterização de frutos de atemoieira em três estádios de maturação cultivados na Chapada do Apodi, Ceará. 2010. Trabalho de Conclusão de Curso TCC. (Monografia). Curso de Tecnologia de Alimentos. IFCE Campus Sobral.

Aguiar, A. O. Processamento e aproveitamento do fruto de araticum (Annona crassiflora L.) em forma de doce em massa. 55fs. Universidade Federal do Tocantins- UFTO. 2018. Dissertação (Mestrado em Ciência e Tecnologia de Alimentos).

Araújo Neto, S. E., Farias, J. F., Álvares, V. G., Ferraz, P. A., Furtado, D. T., \& Souza, M. L. Identificação do ponto de colheita de frutos de envira-caju. Revista Brasileira de Fruticultura. 33 (3), 730-736.

Barbosa, M. C. F., Souza, P. A., Coelho, E. L., Silva, M. S., Sousa, D. V., Freitas, R. V. S., \& Ferreira, E. O. Avaliação do índice de rachadura em atemoia Gefner armazenada a temperatura ambiente. In: III Simpósio Brasileiro de Pós-colheita.

Batista, P. F. Qualidade, compostos bioativos e atividade antioxidante em frutas produzidas no submédio do vale do São Francisco. 2010. Dissertação (Mestrado em Agronomia). Universidade Federal Rural do Semi-Árido. Mossoró, RN.

Chitarra, M. I. F., \& Chitarra, A. B. Pós- colheita de frutas e hortaliças: fisiologia e manuseio. (2a ed.), UFLA, 785p.

Dussán-Sarria, Saul. Resfriamento rápido e armazenamento refrigerado do figo (Ficus carica L.) 'Roxo de Valinhos' e seus efeitos na qualidade da fruta. 2003. 150 p. Tese (Doutorado em Engenharia Agrícola) FEAGRI/UNICAMP.

Farias, J. F., Neto, S. E. A., Álvares, V. S., Ferraz, P. A., Furtado, D. T., \& Souza, M. L. Maturação e determinação do ponto de colheita de Envira-caju. Revista Brasileira de Fruticultura, 33 (3), 733-736.

Giles, J. A. D., Oliari, L. S., Rocha, A. C. B., Schimidilt, E. R., Silva, W., \& França, J. M. Correlações entre características físicas, químicas e físicoquímicas de frutos de cirigueleira. Revista Agro@mbiente On-line, 10 (1) 30-35, 2016.

Hojo, E. T. D., Cardoso, A. D., Hojo, R. H., Vilas Boas, E. V. B., \& Alvarenga, M. A. R. Uso de películas de fécula de mandioca e pvc na conservação póscolheita de pimentão. Revista Ciência e Agrotecnologia, 31 (1), 184-190.

Instituto Adolfo Lutz - IAL. Normas analíticas, métodos químicos e físicos para análise de alimentos. 371.

Lima, M. A. C., Alves, R. E., Filgueiras, H. A. C., \& Enéas Filho, J. Comportamento respiratório e qualidade pós-colheita de graviola (Annona muricata L.) morada sob temperatura ambiente. Revista Brasileira de Fruticultura, 25 (1), 49-52.

Lima, J. A. D. Métodos para conservação de frutas e hortaliças. TCC (Trabalho de Conclusão de Curso). 53fs. Universidade de Brasília. Faculdade de Agronomia e Medicina Veterinária. Brasília- DF, 2016.

Miller. G. L. Use of dinitrosalicylic acid reagent for determination of reducing sugar. Analitical chemistry. 1(31), 426-428.

Mohr, L. C., Spohr, G. M., Quadros, C. F., Mai, S. C., Menoncin, S., Ternus, R., \& Dalcanton, F. Estudo da concentração de fécula de mandioca na utilização em filmes biodegradáveis para o recobrimento de tomates. XX COBEQ - Congresso Brasileiro de Engenharia química.

Prill, M. A. de S., Neves, L. T. B. C., Campos, A. J. de, Silva, S., Chagas, E. A., \& Araújo, W. F. de. Aplicações de tecnologias pós-colheita para bananas Prataanã produzidas em Roraima. Revista Brasileira de Engenharia Agrícola e Ambiental, 16(11), 1237-1242.

Reges, B. M., Batista, E. M., Almeida, E. J. N., Lemos, L. M. R., Silva, E. F., \& Souza, P. A. Pós- colheita de Annona squamosa L. recobertas com filme de PVC. Revista Verde, 13 (4), 445-451, 2018.

Stroencker, R, \& Henning, H. M. Analisis de vitaminas. Metodos comprobados. Paz Montalvo, 428p.

Salvador, T. L., Lemos, E. E. P., Salvador, T. L., \& Rezende, L. Características físico-químicas de Pinha (Annona squamosa L.) cv. Crioula com filme de PVC em diferentes temperaturas. Ciência Agrícola, 16(1), 85-89.

Santos, I. R. C. Escurecimento enzimático em frutos: polifenoloxidases de atemoia (A. cherimola Mill. x A. squamosa L.). 2009. Dissertação (Mestrado em Alimentos e Nutrição). Faculdade de Ciências Farmacêuticas de Araraquara- FCAR/UNESP.

Silva, A. V. C., Andrade, D. G., Yaguiu, P., Carnelossi, M. A. G., Muniz, E. M., \& Narain, N. Uso de embalagens e refrigeração na conservação de atemóia. Revista Ciência e Tecnologia de Alimentos, 29(2), 300-304.

Silva, A. V. C., \& Muniz, E. N. Qualidade de atemóia colhida em dois estádios de maturação. Revista Caatinga, 24(4), 9-13.

Silva, V. X., Durigan, M. F., Tosin, J. M., Vasconcelos, L. L., Coelho, P. C., Fujita, E., Lima, C. G. B., Chagas, E. A., \& Neves, L. C. Conservação de pinha (Annona squamosa L.) em diferentes embalagens e temperatura ambiente e refrigerada. III Simpósio Brasileiro de Pós Colheita. SPC. 2011. Universidade Federal de Roraima. 
Research, Society and Development, v. 10, n. 11, e367101118095, 2021

(CC BY 4.0) | ISSN 2525-3409 | DOI: http://dx.doi.org/10.33448/rsd-v10i11.18095

Siqueira, C. L. Conservação Pós-colheita de Genótipos de bananeira resistente a sigatoka negra por atmosfra modificada, 2008. Dissertação (Mestrado em Produção Vegetal no Semi-árido) - Universidade Estadual de Montes Claros.

Torres, L. M. A. R. Conservação Pós- colheita de atemóia cv. Thompson. 2008. Tese (Mestrado em Alimentos e Nutrição). Universidade Estadual Paulista. Faculdade de Ciências Farmacêuticas. 